\title{
Effect of Hearing Impairment on Behavior and Communication of Children in Schools and Special Education Centers in Mosul City
}

\author{
Hana A. Al-saeed ${ }^{1}$ Rabei M. Al-dobooni ${ }^{2}$ \\ ${ }^{1}$ Post Graduate, Faculty of Nursing/ University of Mosul/Iraq, ${ }^{2}$ Assistant Professor, Faculty of Medicine/ \\ University of Mosul/Iraq
}

\begin{abstract}
Objectives: To identify the effect of hearing impairment on children behavior in daily activities and communication with peers and problems facing teachers of HI children in Iraqi environment. Methods : the strength and difficult questionnaire (SDQ) was used to measure the behavioral, and peer problems questionnaire to measure communication disorders of children with HI based on parents and teachers in (209) children (123) HI and (86) normal hearing control group. Results: on parent teacher questionnaire significantly higher behavioral problems for HI children compared with control group (p-value $\mathbf{0 . 0 4 3}<$ alpha value 0.05) and (chi-square 7.321) so increase the emotional problems (p-value 0.035)and peer problems (0.026) of HI children its highly significant found of behavioral problems, so $65 \%$ of hearing impaired children had communication problems with others and environment. The teachers facing many problems when deals with $\mathrm{HI}$ but the most common one difficult when communicate with them because the limited capabilities available and modern educational methods for teaching the HI children. Conclusions: The majority of hearing impaired children have congenital cause for their hearing loss. Behavior problems appear more common in children with hearing loss and communication problems. The vast majority of teachers agree that there are problems facing students with hearing impairment, and these difficulties need to be dealt with the benefit of their children and the community as a whole.
\end{abstract}

Keywords: hearing impairment, behavioral, communication, Mosul; children; activity.

\section{Introduction}

Hearing Impaired category is an important issue that should have taken enough care in one form or another . Hearing loss is a common problem in all ages and represents a. HI directly affects the quality of life and it is most often manifested in communication difficulties.

deviations in emotional and social development ${ }^{[4]}$.

"WHO has documented and continues to document the increase in the proportion of HI people around the world, estimated that in 2030 the number of people with hearing loss will be around 630 million", and within 2050 the number of injured will be 900 million $^{[10]}$.

Corresponding author:

Rabei M. Al-dobooni

Rabeialdobooni@yahoo.com
The effect of hearing impairment varies according to variables, type and degree of hearing disability, age at which they occur, and the extent to which hearing devices are used ${ }^{[6]}$.

Hearing loss is categorized as mild (20-30 $\mathrm{dB}$ hearing level, HL), moderate (30-50 dB HL), moderately severe (50-70 dB HL), severe (75-85 dB. $\mathrm{HL})$, or profound $(>85 \mathrm{~dB})^{[5]}$.

Recently, the WHO Studies concerned with children had demonstrated that children with hearing loss develop more aggressive behavior ${ }^{[8]}$.

Communication difficulties caused by hearing impairment directly affect the quality of life of affected children. Difficulties in communication can lead to an impairment of emotional and social development. It is well known that good hearing is essential for the 
development of speech and language ${ }^{[1]}$.

\section{Method}

\section{participants}

the study was school based populations (HI) children and normal hearing (control group) (table 1). The selected intentional sample (non-probability) consisted (123) students (64 males) and (59 females) ,selected from several special education centers in Mosul, which was confirmed by medical examination as well the severity and cause of hearing loss, were include in this study, and (86) children (male 55.4\%) and (female $44.6 \%$ ) of the same age group of case samples( 6-12) years as control group in order to compare the behavioral and communication problems. So (50) teachers in the field of special education were selected to answer the questionnaire prepared by the researcher and evaluated by experts to be suitable for the sample community and for the internal consistency of the questionnaire parts.

procedure and measure: After presenting the basic approvals, data were collected by interviewing the hearing impaired students to fill their questionnaire as well as in addition there were several meeting with the teacher to enquire about the child's behavior and to fill the teachers part of the questionnaire. Referral to the student registration data and medical examination when enrolled in the special education classes for the purpose of obtaining the degree of hearing loss and its causes.

\section{measure of behavioral problems}

The present study confirmed the higher behavioral problems for children with HI compared to hearing controls. Children with hearing loss show an elevated level of behavior problems were measured using the Strengths and Difficulties Questionnaire(SDQ) ${ }^{[11]}$.

This is a widely used behavioral screening questionnaire that provides data on children and young people's behaviors, emotions and relationships.

\section{measure of communications problems}

To measure communication problems of (HI) children, the researcher used the "peer relationship questionnaire.

\section{measures of teachers problems facing them.}

To measure the problems facing teachers who deal with the hearing-impaired category, a (12-items) questionnaire was built that obtained acceptable honesty and consistency and evaluation by experts.

\section{Results}

\section{characteristics of the samples}

Table-1 show that there were no statistically significant differences between control group and experimental group where the value of the chi- square test (5.000) and degrees of freedom (6) and the significant value $\mathbf{( 0 . 4 0 3 )}$ more than $\mathrm{p}$ - value $(0.05 \%)$ which indicates the convergence of the homogeneity of the control sample and the experimental group.

Table (1) General characteristics of the children with hearing loss (123) and control group (86).

\begin{tabular}{|c|c|c|c|c|c|c|c|c|}
\hline \multirow[b]{2}{*}{$\mathbf{N}$} & \multirow[b]{2}{*}{ Paragraph } & \multirow[b]{2}{*}{ Var. } & \multicolumn{2}{|c|}{ Hearing impaired } & \multicolumn{2}{|l|}{ Control } & \multirow[b]{2}{*}{$\mathbf{X} 2$} & \multirow[b]{2}{*}{ P-value } \\
\hline & & & $\begin{array}{l}F(\%) \\
(H I) n=123\end{array}$ & $\begin{array}{l}\text { M+S.D } \\
(\mathrm{HI})\end{array}$ & $\begin{array}{l}\mathrm{F}(\%) \\
(\mathrm{NH}) \mathrm{n}=86\end{array}$ & $\begin{array}{l}\text { M+SD } \\
\text { (NH) }\end{array}$ & & \\
\hline \multirow{2}{*}{1} & \multirow{2}{*}{ Gender } & Male & $64(52 \%)$ & \multirow{2}{*}{$1.48(.50)$} & $48(55.8 \%)$ & \multirow{2}{*}{$1.44(.50)$} & \multirow{7}{*}{5.000} & \multirow{7}{*}{0.403} \\
\hline & & Female & $59(48 \%)$ & & $38(44.2 \%)$ & & & \\
\hline \multirow{3}{*}{2} & \multirow{3}{*}{ Age } & $6-7$ years & $34(27.6 \%)$ & \multirow{3}{*}{$2.14(.82)$} & $33(38.4 \%)$ & \multirow{3}{*}{$1.76(.68)$} & & \\
\hline & & $8-10$ years & $38(30.9 \%$ & & $41(47.6 \%)$ & & & \\
\hline & & 11-12 years & $51(41.5 \%)$ & & $12(14.0 \%)$ & & & \\
\hline \multirow{2}{*}{3} & \multirow{2}{*}{$\begin{array}{l}\text { Center/ } \\
\text { School }\end{array}$} & Center & $91(74 \%)$ & \multirow[b]{2}{*}{$1.26(.44)$} & $27(31.4 \%)$ & \multirow[b]{2}{*}{$1.69(.46)$} & & \\
\hline & & School & $32(26 \%)$ & & $59(68.6 \%)$ & & & \\
\hline
\end{tabular}


Table( 2) Hearing impairment children health status information $n=(123)$.

\begin{tabular}{|c|c|c|c|c|c|c|}
\hline S & Paragraph & Var. & $\mathbf{F}$ & $\%$ & Mean & S.D \\
\hline \multirow{4}{*}{1} & \multirow{4}{*}{ Level of loss } & Mild & 18 & $14.6 \%$ & \multirow{4}{*}{2.77} & \multirow{4}{*}{1.039} \\
\hline & & Moderate & 29 & $23.6 \%$ & & \\
\hline & & Severe & 39 & $31.7 \%$ & & \\
\hline & & Profound & 37 & $30.1 \%$ & & \\
\hline \multirow{2}{*}{2} & \multirow{2}{*}{ The age of HL detection } & Less than 3 years & 86 & $69.9 \%$ & \multirow{2}{*}{1.30} & \multirow{2}{*}{0.460} \\
\hline & & More than 3 years & 37 & $30.1 \%$ & & \\
\hline \multirow{4}{*}{3} & \multirow{4}{*}{ Cause of hearing loss } & Idiopathic & 31 & $25.2 \%$ & \multirow{4}{*}{1.33} & \multirow{4}{*}{0.071} \\
\hline & & Disease & 34 & $27.6 \%$ & & \\
\hline & & Congenital & 45 & $36.6 \%$ & & \\
\hline & & Accident & 13 & $10.6 \%$ & & \\
\hline \multirow{2}{*}{4} & \multirow{2}{*}{$\begin{array}{l}\text { What is the disease cause } \\
\text { hearing loss }\end{array}$} & Otitis media & 22 & $64.7 \%$ & \multirow{2}{*}{1.35} & \multirow{2}{*}{0.485} \\
\hline & & Encephalitis & 12 & $35.3 \%$ & & \\
\hline \multirow{2}{*}{5} & \multirow{2}{*}{ child wear a hearing aid } & No & 49 & $39.8 \%$ & \multirow{2}{*}{1.60} & \multirow{2}{*}{0.492} \\
\hline & & Yes & 74 & $60.2 \%$ & & \\
\hline \multirow{2}{*}{6} & \multirow{2}{*}{ Use hearing aid } & One ear & 33 & $44.6 \%$ & \multirow{2}{*}{1.55} & \multirow{2}{*}{0.500} \\
\hline & & Both ears & 41 & $55.4 \%$ & & \\
\hline \multirow{2}{*}{7} & \multirow{2}{*}{$\begin{array}{l}\text { Was the child taken to a } \\
\text { speech therapist }\end{array}$} & Yes & 74 & $60.2 \%$ & \multirow{2}{*}{1.60} & \multirow{2}{*}{0.490} \\
\hline & & No & 49 & $39.8 \%$ & & \\
\hline \multirow{2}{*}{8} & \multirow{2}{*}{$\begin{array}{l}\text { Filling the questionnaire by } \\
\text { parents/teacher }\end{array}$} & Parents & 47 & $38.2 \%$ & \multirow{2}{*}{1.25} & \multirow{2}{*}{0.453} \\
\hline & & Teacher & 76 & $61.8 \%$ & & \\
\hline \multirow{2}{*}{9} & $\begin{array}{l}\text { Does the child have } \\
\text { difficulty in speech? }\end{array}$ & Yes & 81 & $65.85 \%$ & \multirow{2}{*}{1.58} & 0451 \\
\hline & & No & 42 & $34.15 \%$ & & \\
\hline
\end{tabular}

Table(2) show severe to profound hearing loss $(30.1-31.7) \%$. Most of them were diagnosed with a disability at less than (3)years old.(at this age because this age the child begins to communicate with others, speak and start talking). Most of these cases were due to congenital causes (36.6\%) . Most of study children wear hearing aids in both of the ears by(both ear affected) $55.4 \%$. The majority of them live in families without a disability $71.5 \%$ and show a great response about that the child has speech difficulty at $65.85 \%$. 
Medico-legal Update, July-September 2020, Vol.20, No. $3 \mathbf{1 0 6 3}$

Table (3) Teacher / parents information about the behavior of the hearing impaired $n=(123)$ children and normal hearing children $n=(86)$ of study sample

\begin{tabular}{|c|c|c|c|c|c|c|}
\hline \multirow{2}{*}{$\begin{array}{l}\text { Scale } \\
\text { axis }\end{array}$} & \multirow{2}{*}{ Questions } & \multirow{2}{*}{$\begin{array}{l}\text { Sub } \\
\text { averages mean }(\mathrm{HI})\end{array}$} & \multirow{2}{*}{ Total axis } & \multirow{2}{*}{$\begin{array}{l}\text { Sub } \\
\text { average mean }(\mathrm{NH})\end{array}$} & \multirow{2}{*}{$\begin{array}{l}\text { Total } \\
\text { axis }\end{array}$} & $\mathrm{X} 2$ \\
\hline & & & & & & p-value \\
\hline \multirow{5}{*}{ 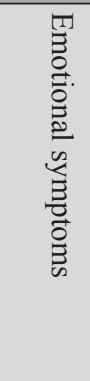 } & Q 3 & 1.67 & \multirow{5}{*}{1.81} & 1.35 & \multirow{5}{*}{1.25} & \multirow{2}{*}{7.321} \\
\hline & Q 8 & 1.79 & & 1.30 & & \\
\hline & Q13 & 1.80 & & 1.22 & & \multirow{3}{*}{0.035} \\
\hline & Q 16 & 1.96 & & 1.24 & & \\
\hline & Q24 & 1.85 & & 1.18 & & \\
\hline \multirow{5}{*}{ 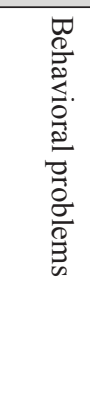 } & Q 5 & 1.93 & \multirow{5}{*}{1.82} & 1.33 & \multirow{5}{*}{1.21} & \multirow{2}{*}{8.120} \\
\hline & Q 7 & 1.85 & & 1.41 & & \\
\hline & Q12 & 1.71 & & 1.18 & & \\
\hline & Q 18 & 1.98 & & 1.13 & & \\
\hline & Q22 & 1.63 & & 1.01 & & 0.043 \\
\hline \multirow{5}{*}{ 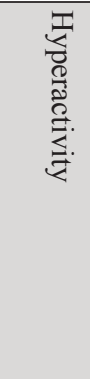 } & Q21 & 1.71 & \multirow{5}{*}{1.77} & 1.61 & \multirow{5}{*}{1.54} & \multirow{2}{*}{10.000} \\
\hline & Q 25 & 1.55 & & 1.44 & & \\
\hline & Q 2 & 1.80 & & 1.53 & & \multirow{3}{*}{0.220} \\
\hline & Q 10 & 1.94 & & 1.28 & & \\
\hline & Q 15 & 1.89 & & 1.67 & & \\
\hline \multirow{5}{*}{ 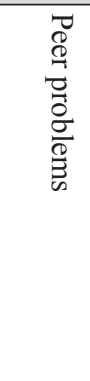 } & Q 11 & 1.82 & \multirow{5}{*}{1.83} & 2.08 & \multirow{5}{*}{1.60} & \multirow{2}{*}{9.989} \\
\hline & Q 14 & 1.80 & & 1.34 & & \\
\hline & Q 6 & 1.72 & & 1.22 & & \\
\hline & Q19 & 1.93 & & 1.34 & & \\
\hline & Q23 & 1.92 & & 2.03 & & \\
\hline \multirow{5}{*}{$\begin{array}{l}\overrightarrow{0} \\
0 \\
0 \\
0 \\
0 \\
0 \\
0 \\
0 \\
0 \\
0 \\
0 \\
0 \\
0 \\
0 \\
0 \\
0 \\
0 \\
0 \\
0\end{array}$} & Q 17 & 1.76 & \multirow{5}{*}{1.75} & 1.64 & \multirow{5}{*}{1.91} & \multirow{2}{*}{8.000} \\
\hline & Q 4 & 1.83 & & 2.05 & & \\
\hline & Q 9 & 1.85 & & 2.06 & & \\
\hline & Q 20 & 1.71 & & 1.92 & & 0.333 \\
\hline & Q 1 & 1.64 & & 1.92 & & \\
\hline
\end{tabular}


\begin{tabular}{l|l} 
Whole average & 1.796
\end{tabular}

Table (3) shows a comparison between control and experimental group by chi-square test to compare the averages, showed the presence of statistically significant differences between the two groups in show include behavior disorder chi-square (8.120) and p-value (0.043). It is less than alpha value $(0.05)$, which indicates the presence of statistically significant differences for behaviors, due to hearing impairment. So the emotional symptoms, showed statistically significant differences between the two groups. The value chi-square to 7.321 with a significant value $(0.035)$, which is smaller than the alpha value (0.05). This indicates the effect of hearing impairment on behaviors.

Table(4) Communication with others and the surrounding environment for hearing impaired and normal hearing children.

\begin{tabular}{|c|c|c|c|c|c|c|c|c|c|c|}
\hline \multirow{2}{*}{ N. } & \multirow{2}{*}{ Qus. } & \multicolumn{2}{|l|}{ (HI) } & \multirow{2}{*}{$\begin{array}{l}\text { Mean } \\
(\mathrm{HI})\end{array}$} & \multirow{2}{*}{$\begin{array}{l}\text { S.D } \\
\text { (HI) }\end{array}$} & \multicolumn{2}{|c|}{ (NH) } & \multirow{2}{*}{$\begin{array}{l}\text { Mean } \\
\text { (NH) }\end{array}$} & \multirow{2}{*}{$\begin{array}{l}\text { S.D } \\
(\mathrm{NH})\end{array}$} & \multirow{2}{*}{$\begin{array}{l}\mathrm{X} 2 \\
\text { p-value }\end{array}$} \\
\hline & & Yes & No & & & Yes & No & & & \\
\hline 1 & Q 1 & $\% 77.2$ & $22.8 \%$ & 1.63 & 0.486 & 82.6 & 17.4 & 1.83 & 0.38 & 6.000 \\
\hline 2 & Q 2 & $\% 65$ & $35 \%$ & 1.65 & $\mid 0.479$ & 72.1 & 27.9 & 1.72 & 0.45 & \\
\hline 3 & Q 3 & $\% 66.7$ & $33 \%$ & 1.67 & 0.490 & 89.5 & 10.5 & 1.90 & 0.30 & 0.423 \\
\hline 4 & Q 4 & $59.3 \%$ & $40.7 \%$ & 1.41 & 0.493 & 67.4 & 32.6 & 1.67 & 0.47 & \\
\hline 5 & Q 5 & $56.9 \%$ & $43 . \%$ & 1.57 & 0.497 & & & & & \\
\hline 6 & Q 6 & $76.4 \%$ & $23.6 \%$ & 1.76 & 0.426 & & & & & \\
\hline 7 & Q 7 & $64.2 \%$ & $35.8 \%$ & 1.64 & 0.481 & & & & & \\
\hline 8 & Q 8 & $65 \%$ & $35 \%$ & 1.65 & 0.479 & & & & & \\
\hline 9 & Q 9 & $62.6 \%$ & $37.4 \%$ & 1.63 & 0.486 & & & & & \\
\hline 10 & Q 10 & $59.3 \%$ & $40.7 \%$ & 1.59 & 0.493 & & & & & \\
\hline 11 & Q 11 & $52 \%$ & $48 \%$ & 1.52 & 0.502 & & & & & \\
\hline
\end{tabular}

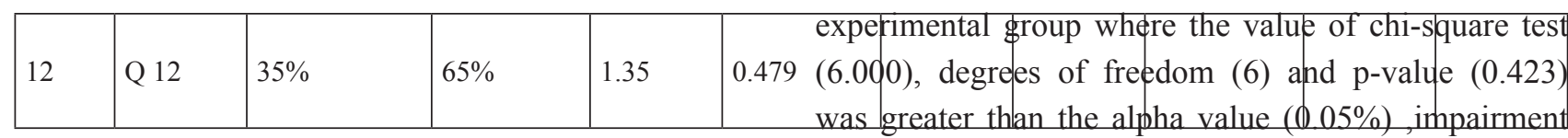

Table (4) explain the first four paragraphs(Hearing impaired children group and control group) that include both groups there were no statistically significant differences between the control group and the greatly affects the relationship of students with friends and affects communication with others in the school and the surrounding environment, according to the majority of responses to questionnaire items with a number of 80 
responses with a rate of (65\%), with a general average of (1.60).

Table (5) The teachers 'responses regarding the hearing impaired children, the problems and challenges.

\begin{tabular}{|c|c|c|c|c|c|}
\hline \multirow{2}{*}{ N. } & \multirow{2}{*}{ Paragraph } & \multicolumn{2}{|c|}{ Responses } & \multirow{2}{*}{ Mean } & \multirow{2}{*}{ S.D } \\
\hline & & Yes & No & & \\
\hline 1 & Are you a graduate of special education & $44 \%$ & $56 \%$ & 1.44 & 0.051 \\
\hline 2 & $\begin{array}{l}\text { Do you have in the center modern means to educate people } \\
\text { with hearing impairment }\end{array}$ & $38 \%$ & $62 \%$ & 1.38 & 0.490 \\
\hline 3 & Are you talking to them and directing them loudly & $74 \%$ & $26 \%$ & 1.74 & 0.443 \\
\hline 4 & $\begin{array}{l}\text { Do you support setting up courses for teachers to train them } \\
\text { in forms of communication with the them? }\end{array}$ & $86 \%$ & $14 \%$ & 1.86 & 0.351 \\
\hline 5 & $\begin{array}{l}\text { Do you support the presence of a speech specialist in special } \\
\text { education centers and schools }\end{array}$ & $70 \%$ & $30 \%$ & 1.70 & 0.483 \\
\hline 6 & $\begin{array}{l}\text { Do you see progress in the field of special education in the } \\
\text { city of Mosul }\end{array}$ & $40 \%$ & $60 \%$ & 1.40 & 0.495 \\
\hline 7 & Is your center better from other centers in the city & $52 \%$ & $48 \%$ & 1.52 & 0.505 \\
\hline 8 & $\begin{array}{l}\text { From your point of view as a special education teacher, is it } \\
\text { easy to deal with the hard of hearing class }\end{array}$ & $32 \%$ & $68 \%$ & 1.32 & 0.471 \\
\hline 9 & $\begin{array}{l}\text { Would the results of such studies benefit the hearing } \\
\text { impaired group }\end{array}$ & $60 \%$ & $40 \%$ & 1.60 & 0.495 \\
\hline
\end{tabular}

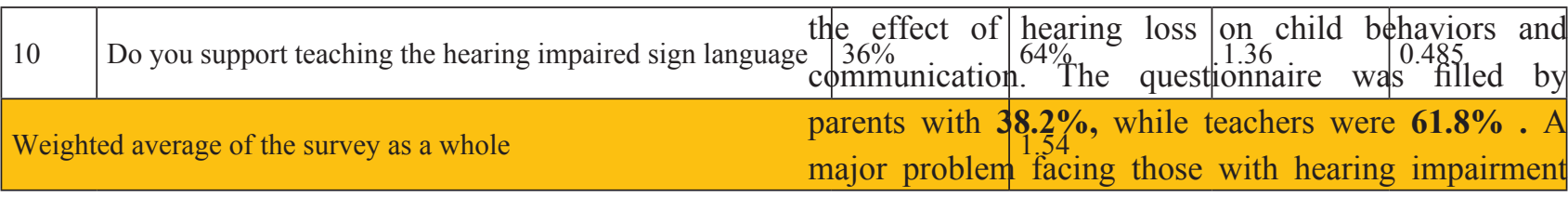

Table (5) show the opinions of hearing impaired teachers that agree on the presence of problems and challenges facing the hearing impaired in the local environment by $60 \%$ and the number of responses exceeding 30 responses, with a general average (1.54) and standard deviation (0.203). Also, the responses of dealing with the hearing impaired category was "not easy" in $68 \%$ of the teacher and talking to them loudly and repeatedly causes them stress $74 \%$.

\section{Discussion}

The purpose of the present study is to determine is the effect on speech, where the percentage of those who had difficulty speaking and talking was $\mathbf{6 5 . 8 5} \%$. Another effect of hearing impairment which was shown in the present study is behavior by mean (1.79) and communication by problems that effect $(65 \%)$ of the studied children. This can have deleterious effect on academic achievement as well as psychological wellbeing.

\section{level of hearing loss}

The levels of hearing loss were severe to profound by 30.1_30.7\%.(table 2) Most of them were diagnosed with a disability less than 3years old, (because this age 
the child begins to communicate with others, speak and start talking). These results are consistent with study of ${ }^{[6]}$. The percentage of children with severe hearing loss

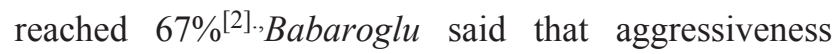
varies depending on age and level hearing impairment and children with profound $(81 \mathrm{db})$ hearing impairment show more aggressive behaviors at older ages (10-15 age) compared to normal hearing children.

\section{Behavioral effect}

(Table 3) showed the parents / teachers' opinions on the behavioral questionnaire for the hearing impaired children. SDQ contains sub-scale from 5 parts which are problems (behavioral, emotional, hyperactivity, peer relationship, social behavior). Each part of these problems contains 5 points that assess if the child has any of these symptoms or not. In the present study the participants agreed on the presence of emotional symptoms in the behavior of children with hearing impairment with an average of(1.81), and slight increased hyperactivity with an average of (1.77). Behavioral problems and aggression with the peers was highest found with average (1.82), the first four axes represent the negative behavior in the child's personality. In the Fifth part of the questionnaire the participants agreed on the existence of positive personal social behavior with an average (1.75) and a standard deviation (0.426).

\section{communication effect}

(Table 4) show that HI affects the relationship of majority students with peers and affects communication (80) responses with a general average of (1.60). This means that hearing impairment has effects on the relationship and communication with others and the surrounding environment, leading to constriction in social relationships with others and makes children more isolated(65\%). The majority of children avoid communicate with peers because mocked him due to he had hearing loss and felt embarrassed about the hearing aids, which makes him avoid the gatherings of children by responding $(62 \%)$ of the whole population sample, and difficulty communication with others when crowded environment rate $\mathbf{6 5 \%}$. This finding is consistent with a study ${ }^{[3]}$. which documented communication problems in noisy setting such as family setting room or classrooms.

\section{Teachers' perspectives and challenges facing}

them.

(Table 5) showed $65 \%$ of the teachers are not graduates of special education and this means that not all teachers have sufficient experience to deal with the hearing impaired group in a correct routs. Seventy four percent of the teachers (74\%) need to speak loudly repeatedly which result stress. It was found that the vast majority of teachers support conducting training courses in this field for them in order to deal with the hearing impaired in a correct scientific manner, and the response is $86 \%$, with mean of 1.36 , they also support the presence of a speech therapist in every center and school, with mean 1.70 and percentage $70 \%$. The teachers do not see progress in the field of special education in the city of Mosul.The majority of teachers do not support teaching the hearing impaired the "sign language») $\mathbf{6 4 \%}$ (may be explained by the fact that the hearing impaired child who have hearing residue will use the sign language as an easier and faster.

\section{Conclusions}

The majority of hearing impaired children have congenital cause for their hearing loss. Idiopathic cause have next and less common cause is otitis media. Behavior problems appear more common in children with hearing loss, the results of the current study showed an increase in behavioral problems among the hearing impaired and this problems limits their relationship with others. So the results of the study showed the opinions of teachers about centers and schools for the hearing impaired in the city of Mosul.

Acknowledgment: I thank the children who participated in this study, the teachers and the parents. And big thanks to the supervisors of Dr. Rabei M. Aldobooni.

Ethical Clearance: The Research Ethical Committee at scientific research by ethical approval of both MOH and MOHSER in Iraq

\section{Conflict of Interest: Non}

Funding: Self-funding

\section{References}

1. Aras, I., Stevanović, R., Vlahović, S., Stevanović, S., Kolarić, B., \& Kondić, L.. Health related 
quality of life in parents of children with speech and hearing impairment. International journal of pediatric otorhinolaryngology, 2014 ;78(2), 323329.

2. Babaroglu, A. Aggression behaviors in children with and without hearing impairment. Int J Psychol Stud,2016; 8(2), 14-24.

3. Hogan, A., Shipley, M., Strazdins, L., Purcell, A., \& Baker, E. Communication and behavioural disorders among children with hearing loss increases risk of mental health disorders. Australian and New Zealand journal of public health,2011; 35(4), 377-383?

4. Jasenka B., \& Jagoda D., Communication Problems and Quality of Life People with Hearing Loss.global journal of otolaryngology.2016;pp (8).
5. Kliegman, R. M., Lye, P. S., Bordini, B. J., Toth, H., \& Basel, D. Nelson Pediatric SymptomBased Diagnosis E-Book. Elsevier Health Sciences,2017;pp(1213).

6. Kral, A., Popper, A. \& Fay, R. (eds.) Deafness. New York, London: Springer,2013;pp(84).

7. Meinzen-Derr, J., Wiley, S., Grether, S., Phillips, J., Choo, D., Hibner, J., \& Barnard, H. Functional communication of children who are deaf or hardof-hearing. Journal of Developmental \& Behavioral Pediatrics,2014; 35(3), 197-206.

8. Theunissen, S. C., Rieffe, C., Netten, A. P., Briaire, J. J., Soede, W., Schoones, J. W., et al. Psychopathology and its risk and protective factors in hearingimpaired children and adolescents: a systematic review. JAM Pediatr.2014; 168,A170177. doi: 10.1001/jamapediatrics. 2013;3974.

9. World health organization,(2018) retrieved on 22,january 2020 from www.who.int/deafness/ world-hearing-day/whd-2018/en .

10. Goodman, R. Retrieved on 2009, July SDQ information website, (2002).. 